\title{
Modeling Stock Market Volatility Using GARCH Models: A Case Study of Nairobi Securities Exchange (NSE)
}

\author{
Arfa Maqsood ${ }^{1}$, Suboohi Safdar ${ }^{1}$, Rafia Shafi ${ }^{1}$, Ntato Jeremiah Lelit ${ }^{2}$ \\ ${ }^{1}$ Department of Statistics, University of Karachi, Karachi, Pakistan \\ ${ }^{2}$ Actuarial Science and Risk Management, University of Karachi, Karachi, Pakistan \\ Email: amaqsood@uok.edu.pk
}

How to cite this paper: Maqsood, A., Safdar, S., Shafi, R. and Lelit, N.J. (2017) Modeling Stock Market Volatility Using GARCH Models: A Case Study of Nairobi Securities Exchange (NSE). Open Journal of Statistics, 7, 369-381.

https://doi.org/10.4236/ojs.2017.72026

Received: March 21, 2017

Accepted: April 27, 2017

Published: April 30, 2017

Copyright $\odot 2017$ by authors and Scientific Research Publishing Inc. This work is licensed under the Creative Commons Attribution International License (CC BY 4.0).

http://creativecommons.org/licenses/by/4.0/

\begin{abstract}
The aim of this paper is to use the General Autoregressive Conditional Heteroscedastic (GARCH) type models for the estimation of volatility of the daily returns of the Kenyan stock market: that is Nairobi Securities Exchange (NSE). The conditional variance is estimated using the data from March 2013 to February 2016. We use both symmetric and asymmetric models to capture the most common features of the stock markets like leverage effect and volatility clustering. The results show that the volatility process is highly persistent, thus, giving evidence of the existence of risk premium for the NSE index return series. This in turn supports the positive correlation hypothesis: that is between volatility and expected stock returns. Another fact revealed by the results is that the asymmetric GARCH models provide better fit for NSE than the symmetric models. This proves the presence of leverage effect in the NSE return series.
\end{abstract}

\section{Keywords}

Nairobi Securities Exchange (NSE), Symmetric and Asymmetric GARCH Models, Volatility, Leverage Effect

\section{Introduction}

Modeling and forecasting volatility in financial time series have become an area that has attracted a lot of researches in both empirical and theoretical aspects. In this situation, the models established to capture the variations in conditional mean of financial time series become no longer useful and hence, the performance of such mean models is reduced to give accuracy in estimation process. Engle [1] first identified this dilemma and presented an equation of variance 
which helped to capture the volatility in the series. He observed the autoregressive effect in conditional variance and suggested an autoregressive conditional heteroscedasticity (ARCH) process using lag disturbances. Since the publication of ARCH model on the subject, there has been a lot of research work done in this area. Some limitations of ARCH model are identified and listed by Brooks [2], and Tsay [3]. The empirical evidence based on Engle's work showed that an $\mathrm{ARCH}$ process of high order was needed to capture the dynamic behavior of conditional variance. Thus, Bollerslev [4] proposed an extension of the $\mathrm{ARCH}$ type model which was called Generalized Autoregressive Conditional Heteroscedasticity (GARCH) model. The GARCH model has fulfilled this requirement since it is based on the infinite ARCH specifications. Many useful properties of GARCH models are given by Posedel [5], Enders [6], and Patterson [7].

ARCH and GARCH models are used to capture both volatility and leptokurtosis. The so called "leverage effect" is also often observed in the financial time series (see Black [8]). This usually occurs when stock price changes are negatively correlated with changes in volatility. Since ARCH and GARCH models are symmetric in nature, they fail to capture the leverage effect. In order to address this problem, many nonlinear extensions of the GARCH models have been proposed. These include asymmetric class of GARCH models such as exponential GARCH (EGARCH) model by Nelson [9], the so-called GJR model by Glosten et al. [10] and the power GARCH (PGARCH) model by Ding et al. [11]. In the light of these observations in the financial time series, a wide range of varying variance models have been used to estimate and predict volatility.

Financial time series have the property of thick tails which are thicker than those of the normal distribution. The other problem encountered by the GARCH model is that they do not fully embrace this property of thick/heavy tails which are so much evident in the behavior of financial time series. To address this problem, again Bollerslev [12], Baillie and Bollerslev [13] used the Student's t-distribution and non normal distribution. Liu and Brorsen [14] used an asymmetric stable density to capture skewness. Fernandez and Steel [15] used the skewed Student's t-distribution to model both skewness and kurtosis.

Today, the emphasis is mostly given towards the application of heteroscedastic models to the financial data. A large number of empirical studies have been accomplished to address the concept of volatility of stock markets using the family of ARCH/GARCH processes. The progress in such studies is provided for the purpose of estimation and prediction of the conditional variance of stock returns over the specified period. The volatility analysis of stock markets is important for the investors in measuring and managing market risks more accurately which, in turn is useful in pricing capital assets, financial securities, and selecting portfolios. For instance, the reader might get benefit from the research done by Ahmed and Suliman [16], Naimy [17], Shamiri and Isa [18], and Kalu [19]. They used some models from GARCH family both symmetric and asymmetric to capture the stock market volatility. Ahmed and Suliman [16] worked with the reference of Sudan stock market, while Kalu [19] provides the volatility analysis 
of Nigerian stock exchange. Modeling volatility of Paris stock market using GARCH $(1,1)$ and compared with exponential weighted moving average (EWMA) was done by Naimy [17]. Similarly, Shamiri and Isa [18] provide the comparison of usual GARCH model with the non linear asymmetric NAGARCH models based on Malaysian stock market. Another study by Wagala et al. [20] considers the Nairobi securities exchange (NSE) weekly returns using ARCH-type models. See also Sharma and Vipul [21].

The main objective of this paper is to model stock returns volatility for the Kenya's Nairobi Securities Exchange (NSE), by applying different univariate specifications of GARCH type models. The rest of this paper is organized as follows. Following this introduction, Section 2 provides a brief review of the methodology of modeling volatility using some well known symmetric and asymmetric GARCH models. A general overview of Nairobi Securities Exchange is provided in Section 3. The description of data and summary statistics are also presented in the same section. The results of the estimated GARCH models are discussed in Section 3.3. Lastly, Section 4 concludes the paper.

\section{Methodology of Modeling Volatility}

Since the development of GARCH models, a number of extensions and variants have been proposed. These variants are well classified in one of the two broad classes of symmetric and asymmetric GARCH models. Before we discuss these extensions, let us assume some notations that are useful to describe the general GARCH framework. Let $\varepsilon_{t}$ denote a real valued discrete time stochastic process and $\psi_{t}$ is the information set of all information through time $t$. We define the model that contains the features of both conditional mean and conditional variance as given below.

$$
r_{t}=E\left(r_{t} / \psi_{t-1}\right)+\varepsilon_{t} ; \varepsilon_{t} \sim N\left(0, \sigma_{t}^{2}\right)
$$

Equation (1) can be rewritten as

$$
r_{t}=\mu_{t}+\varepsilon_{t}
$$

Here, $\mu_{t}=E\left(r_{t} / \psi_{t-1}\right)$ is the expression used to model the conditional mean of $r_{t}$ given that the information through time $t-1$. The error is assumed to be non constant quantity with respect to time and thus given by

$$
\varepsilon_{t}=\sigma_{t} a_{t}
$$

where $\sigma_{t}=\sqrt{V\left(r_{t} / \psi_{t-1}\right)}$ and $a_{t} \sim N(0,1)$. Keeping Equation (2) as for modeling the conditional mean of return, we briefly present a number of specifications of GARCH models to represent the situations for expressing the conditional variance. These are given by the following sub-sections.

\subsection{Symmetric GARCH Models}

In the symmetric GARCH models, the conditional variance only depends on the magnitude of the underlying asset and not on the sign. This ignores the effect raised by the positive or negative asset on conditional variance. The widely used 
symmetric GARCH models include generalized autoregressive conditional heteroscedasticity (GARCH) model and GARCH in mean model. These are discussed below.

\subsubsection{GARCH Models}

A generalized autoregressive conditional heteroscedasticity (GARCH) model is the first and basic symmetric model developed by Bollerslev [4]. It is defined as the linear function of past squared residuals and the lagged conditional variances as given below

$$
\sigma_{t}^{2}=\alpha_{0}+\sum_{i=1}^{q} \alpha_{i} \varepsilon_{t-i}^{2}+\sum_{i=1}^{p} \beta_{i} \sigma_{t-i}^{2}
$$

where $\alpha_{0}$ is the constant term, $\alpha_{1}, \alpha_{2}, \cdots, \alpha_{q}$ are the parameters or coefficients of ARCH specifications, and $\beta_{1}, \beta_{2}, \cdots, \beta_{p}$ are the parameters or coefficients of GARCH specifications. The $q$ and $p$ are the respective orders of ARCH and GARCH processes.

The simplest specification of this model is $\operatorname{GARCH}(1,1)$ model, that is,

$$
\sigma_{t}^{2}=\alpha_{0}+\alpha_{1} \varepsilon_{t-1}^{2}+\beta_{1} \sigma_{t-1}^{2} .
$$

\subsubsection{GARCH-in-Mean (GARCH-M) Models}

Another well known symmetric model is GARCH in Mean (GARCH-M) model developed by Engle, et al. [22]. In most of the financial markets, we expect risk to be compensated by a higher return and hence the return of a security may depend on its volatility. To model such phenomenon one might consider GARCH$M$ model. This variant of GARCH family allows the conditional mean of return series to depend on its conditional variance. A simple GARCH-M $(1,1)$ model is defined by the two equations, the one for conditional mean is given by

$$
r_{t}=\mu_{t}+\varepsilon_{t} \text { where } \mu_{t}=\mu+\lambda \sigma_{t}^{2} .
$$

The equation for conditional variance is same as provided by the GARCH ( $p$, q) model in Equation (4) and its specific case GARCH $(1,1)$ by Equation (5).

\subsection{Asymmetric GARCH Models}

This section deals with the asymmetric models that are extensively motivated by the need to distinguish between good news and bad news and their impact on volatility in financial markets. Engle, and $\mathrm{Ng}$, [23] introduced the news impact curve and summarized the effect of a shock interpreted as negative shocks (bad news) or a positive shock (good news) on the time varying conditional variance. For many stock returns, there is a negative correlation between the current return and the future volatility. The tendency of volatility to decline when return rises and to rise when return falls is called the leverage effect. Symmetric models fail to explain the leverage effect due to incapability of conditional variance to respond asymmetrically. Consequently, many asymmetric variants of GARCH models have been established to deal with this phenomenon. Some of them are discussed below. 


\subsubsection{Exponential GARCH (EGARCH) Models}

Nelson [9] proposed the exponential GARCH (EGARCH) models particularly designed to allow asymmetric effect between positive and negative asset returns. The EGARCH $(\mathrm{p}, \mathrm{q})$ specification is given by

$$
\left.\log \left(\sigma_{t}^{2}\right)=\alpha_{0}+\sum_{i=1}^{q} \alpha_{i}\left[\mid \frac{\varepsilon_{t-i}}{\sigma_{t-i}}\right]\right]+\sum_{i=1}^{p} \beta_{i} \log \left(\sigma_{t-i}^{2}\right)+\sum_{i=1}^{q} \gamma_{i} \frac{\varepsilon_{t-i}}{\sigma_{t-i}}
$$

where $\gamma_{i}$ is the asymmetric or leverage effect parameter. The value of conditional variance will be positive even if the parameters are negative because it models the log of conditional variance. If the relationship between the current return and future volatility is negative then $\gamma$ will be negative and hence the leverage effect is confined.

\subsubsection{Threshold GARCH (TGARCH) Models}

Another important volatility model commonly used to handle the leverage effect is the threshold GARCH (TGARCH) model. This model is developed by Glosten, Jagannathan, and Runkle in 1993 so that it is also called GJR model (see Zakoian [24]). The TGARCH $(p, q)$ framework of conditional variance is given by

$$
\sigma_{t}^{2}=\alpha_{0}+\sum_{i=1}^{q} \alpha_{i} \varepsilon_{t-i}^{2}+\sum_{i=1}^{p} \beta_{i} \sigma_{t-i}^{2}+\sum_{i=1}^{q} \gamma_{i} \varepsilon_{t-i}^{2} I_{t-i}
$$

where $I_{t-i}=1$, if $\varepsilon_{t-i}<0$, otherwise $I_{t-i}=0$, and $\gamma_{i}$ is the parameter of leverage effect. If $\gamma_{i}=0$, the model collapses to the classical $\operatorname{GARCH}(p, q)$ process. Otherwise, when the shock is positive, the effect on volatility is $\alpha_{i}$ (i.e. $I_{t-i}=0$ ), and when the shock is negative, the effect on volatility is $\alpha_{i}+\gamma_{i}$ (i.e. $\left.I_{t-i}=1\right)$. Hence, we can say that for $\alpha_{i}>0$, the effect of bad news have larger impact on conditional variance than does good news.

\subsubsection{Power GARCH (PGARCH) Models}

Ding, et al. [11] proposed a variant to asymmetric GARCH models and provided with power GARCH (PGARCH) models. Unlike the GARCH family, we are able to model both the conditional standard deviation as well as conditional variance. The PGARCH $(p, q)$ specification is as under;

$$
\sigma_{t}^{\delta}=\alpha_{0}+\sum_{i=1}^{q} \alpha_{i}\left(\left|\varepsilon_{t-i}-\gamma_{i} \varepsilon_{t-i}\right|\right)^{\delta}+\sum_{i=1}^{p} \beta_{i} \sigma_{t-i}^{\delta}
$$

where $\delta$ is the parameter for power term such that $\delta>0$. For $\delta=2$, the model simply becomes a standard GARCH model that allows for leverage effect. For $\delta=1$, we deal with the model used to estimate the conditional standard deviation rather conditional variance.

\section{Modeling Volatility of Nairobi Securities Exchange}

\subsection{An Overview of Nairobi Securities Exchange}

Nairobi Securities Exchange is the only stock exchange of Kenya. It is abbreviated as NSE. It was started as Nairobi Stock Exchange in 1954 as a voluntary association of stockbrokers in the European community registered under the 
Societies Act. This was when Kenya was still a British colony. It changed its name to Nairobi Securities Exchange in July 2011. It is based in Nairobi the capital city of Kenya. The principle index of NSE is the NSE 25 Share Index. It uses the local currency (Kenyan shilling) for its operations and on $24^{\text {th }}$ October 2014, it had a market capitalization of about Ksh 2.248 trillion. NSE is the leading securities exchange in East Africa.

Securities traded in NSE are ordinary shares and investment units. There are other products also available and being traded at the NSE which include derivative securities and debt securities which include government bonds. NEXT is the Nairobi Securities Exchange Derivatives market where members can trade future contracts across variety of asset classes such as equities, currencies and fixed income securities. It is regulated by the Central Bank of Kenya (CBK).

The self-listing of NSE stock through an IPO on $27^{\text {th }}$ June 2014 , made the NSE to join the Johannesburg Stock Exchange being the only exchange in Africa that is self-listed. In March 2015, the NSE officially joined the United Nations Sustainable Stock Exchanges (SSE) initiative whereby they made a voluntary pledge to inform their stakeholders of the importance of integrating sustainability in their capital markets.

\subsection{Data Description and Basic Statistics}

The time series data used for modeling volatility in this paper is the daily closing prices of Nairobi Securities Exchange (NSE) index over the period from 18th March 2013 to $18^{\text {th }}$ February 2016, resulting in total observations of 730 excluding public holidays. The daily returns $\left(r_{t}\right)$ are calculated as the continuously compounded returns which are the first differences of log prices of NSE-Index of successive days:

$$
r_{t}=\log \left(\frac{p_{t}}{p_{t-1}}\right)
$$

where $p_{t}$ and $p_{t-1}$ are respectively the closing market index of NSE at the current day and previous day. Various descriptive statistics are calculated and reported in Table 1. This is in order to specify the descriptive properties of the daily NSE return series $\left(r_{t}\right)$ during the period of the study. The mean return is

Table 1. Various descriptive statistics of NSE daily return series.

\begin{tabular}{cc}
\hline Descriptive statistics & Values \\
Mean & 0.000129 \\
Median & $1.08 \mathrm{e}-05$ \\
Maximum & 0.03735 \\
Minimum & -0.03749 \\
Standard deviation & 0.00322 \\
Skewness & -0.11621 \\
Kurtosis & 52.2665 \\
Jarque-Bera (Prob.) & $73727.59(0.0000)$ \\
\hline
\end{tabular}


0.000297 with the standard deviation of 0.007429 . There is also an excess in kurtosis as can be seen clearly. A high value of kurtosis 52.377 indicates a leptokurtic distribution that is an apparent departure from normality. Another important test of normality is the Jarque-Bera (JB) statistic, which confirms the null hypothesis of normality for the daily NSE returns should be rejected at $1 \%$ level of significance. We can thus summarize that the NSE return series do not conform to normality but actually tend to have positive skewness (i.e. the distribution has a thick tail). The plot of NSE daily returns is displayed in Figure 1. We observe a large swing in the period of April 2015 with maximum and minimum returns are respectively 0.0373 and -0.0374 .

\subsection{Analysis of NSE Return}

In order to analyze the return series, the first step is to check the stationary scenario of return series. For this purpose, we employed the familiar Augmented Dickey Fuller (ADF) test and Phillips Perron (PP) test for original series $\left(p_{t}\right)$ and the return series $\left(r_{t}\right)$. The test results are presented in Table 2. The series $\left(p_{t}\right)$ is not stationary, however the results for return $\left(r_{t}\right)$ led towards the rejection of null hypothesis of unit root, and hence stationarity is present in return series.

It is important to examine the residuals to find the evidence of possible heteroscedasticity before applying the methodology of modeling conditional variance. In order to test the presence of heteroscedasticity in the residuals of NSE index returns series, the Lagrange Multiplier (LM) test is applied to test the hypothesis that $\alpha_{1}=\alpha_{2}=\cdots=\alpha_{q}$, where $\mathrm{q}$ is the order of $\mathrm{ARCH}$ effect. The test procedure entails first obtaining the residuals $\hat{\varepsilon}_{t}$ from the ordinary least square regression of the conditional mean equation which might be an autoregressive (AR) process, moving average (MA) process, or a combination of the two processes termed as ARMA process. We assume a constant mean model for modeling the conditional mean and the LM test is applied to compute the test statistic value $T R^{2}$, where $T$ is the number of observations and $R^{2}$ is the coefficient of multiple correlation obtained from regressing the squared residuals on $q$ own lagged values. The test statistic is evaluated against chi-square $\ell^{2}(q)$ distribution

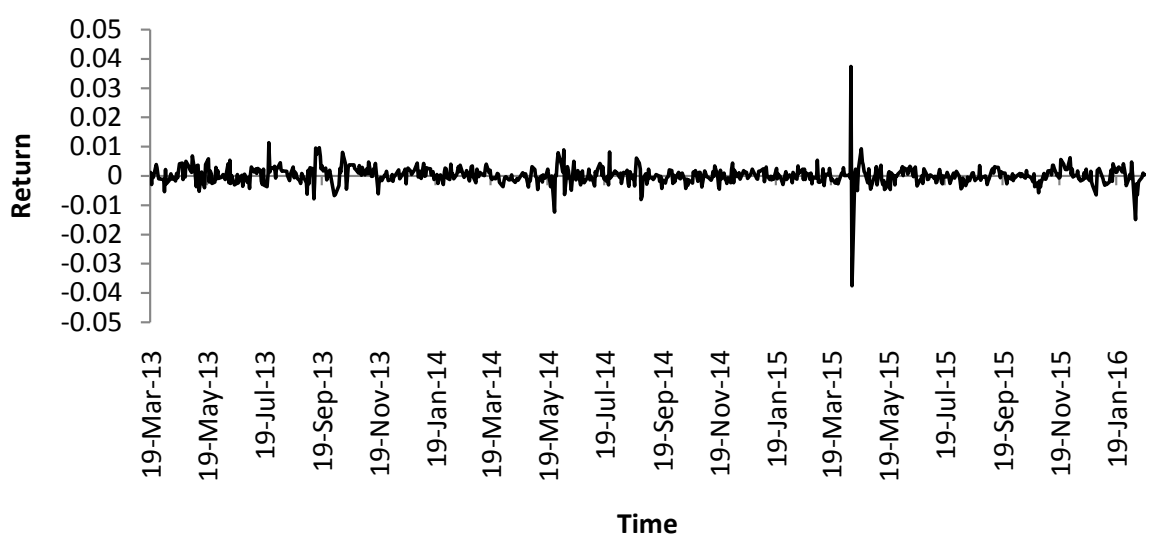

Figure 1. Time plot of NSE daily return series. 
(see Patterson (2000) for details on ARCH-LM test). The results of LM test for various ARCH order $q$ are presented in Table 3, which provide strong evidence of rejecting the null hypothesis of constant variance for all lags included. Rejecting $H_{0}$ indicates the presence of $\mathrm{ARCH}$ effect in the residuals series and therefore we can conclude that the variance of the return of NSE index is no-constant for all periods specified.

Once the volatility is confirmed in data, we proceed our analysis further to estimate the parameters of both conditional mean and conditional variance equations. For this purpose, we employed the symmetric and asymmetric GARCH models including GARCH $(1,1)$, GARCH-M $(1,1)$, EGARCH $(1,1)$, TGARCH $(1,1)$, and PGARCH $(1,1)$. The estimation procedure uses the Broyden-Fletcher-Goldfarb-Shanno (BFGS) optimization method useful for solving unconstrained non-linear problems. The estimation results are presented in Table 4. The constant mean parameter in mean equation is not significant in any of these underlying models. However, we observe the significant constant $\left(\alpha_{0}\right)$, significant ARCH effect $\left(\alpha_{1}\right)$, and significant GARCH effect $\left(\beta_{1}\right)$ in conditional variance equation of GARCH $(1,1)$, GARCH-M $(1,1)$, EGARCH $(1,1)$, and TGARCH $(1,1)$. There is an insignificant contribution of GARCH effect in conditional mean of GARCH-M $(1,1)$ model and also the estimates of conditional variance equations in GARCH $(1,1)$, and GARCH-M $(1,1)$ are observed similar. Therefore, due to insignificant GARCH in mean model one has to prefer the simple parsimonious GARCH $(1,1)$ model. The estimated power parameter $(\delta)$ in Power GARCH model is found to be 3.697 which is significant at $5 \%$ level. However, PGARCH model provides only significant GARCH effect and does not offer the considerable contribution of lag squared disturbances that is the $\mathrm{ARCH}$ effect. The leverage effect $(\gamma)$ is estimated for three asymmetric GARCH models

Table 2. Results of unit root test for original NSE index series, and NSE return series.

\begin{tabular}{cccccc}
\hline \multirow{2}{*}{ Time series } & Test statistic & P-value & \multicolumn{2}{c}{ Critical values } & $\begin{array}{c}\text { Dur- } \\
\text { bin-Watson }\end{array}$ \\
\cline { 3 - 5 } & & & $1 \%$ & $5 \%$ & Test \\
\hline NSE prices & -2.354 & 0.155 & -3.3439 & -2.865 & 2.130 \\
NSE return & $-28.042^{*}$ & 0.000 & -3.439 & -2.865 & 1.991 \\
& & Augmented dickey fuller test & \\
NSE prices & -2.357 & 0.154 & -3.3439 & -2.865 & 2.130 \\
NSE return & $-28.043^{*}$ & 0.000 & -3.439 & -2.865 & 1.991 \\
\hline
\end{tabular}

* Significant at both levels of $1 \%$ and $5 \%$.

Table 3. Results of ARCH-LM test for different values of $q$.

\begin{tabular}{ccc}
\hline ARCH order $q$ & Test statistic TR $^{2}$ & Probability \\
\hline 1 & 166.942 & 0.0000 \\
2 & 216.89 & 0.0000 \\
3 & 236.186 & 0.0000 \\
\hline
\end{tabular}


Table 4. Estimation results of GARCH $(1,1)$, GARCH-M $(1,1)$, EGARCH $(1,1)$, TGARCH $(1,1)$, and PGARCH $(1,1)$ models.

$$
\begin{gathered}
\operatorname{GARCH}(1,1) \\
r_{t}=0.00014 \\
\sigma_{t}^{2}=3.58 \times 10^{-6} * *+0.1082 * * \varepsilon_{t-1}^{2}+0.4964 * * \sigma_{t-1}^{2} \\
\operatorname{GARCH}-\mathrm{M}(1,1) \\
r_{t}=0.000426-32.047 \sigma_{t}^{2} \\
\sigma_{t}^{2}=3.91 \times 10^{-6} * *+0.1113 * * \varepsilon_{t-1}^{2}+0.455^{* *} \sigma_{t-1}^{2} \\
\operatorname{EGARCH}(1,1) \\
r_{t}=0.00023 \\
\log \left(\sigma_{t}^{2}\right)=-10.656 * *+0.2484 * *\left|\frac{\varepsilon_{t-1}}{\sigma_{t-1}}\right|+0.1007 \log \left(\sigma_{t-1}^{2}\right)+0.0506 \frac{\varepsilon_{t-1}}{\sigma_{t-1}} \\
\operatorname{TGARCH}(1,1) \\
r_{t}=0.00013 \\
\sigma_{t}^{2}=3.278 \times 10^{-6 * *+0.1388 * *} \varepsilon_{t-1}^{2}+0.5472 * * \sigma_{t-1}^{2}-0.1076 * \varepsilon_{t-1}^{2} I_{t-1} \\
\operatorname{PGARCH}(1,1) \\
r_{t}=0.00013 \\
\sigma_{t}^{\delta}=2.118 \times 10^{-10}+0.0528\left(\left|\varepsilon_{t-1}+0.165 \varepsilon_{t-1}\right|\right)^{\delta}+0.3756 * \sigma_{t-1}^{\delta} ; \quad \text { where, } \delta=3.697 *
\end{gathered}
$$

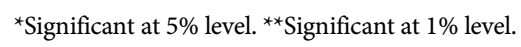

taking the values $0.0506,-0.1076$, and 0.165 respectively for EGARCH, TGARCH, and PGARCH models. We found significance only for TGARCH $(1,1)$ process that confirms the leverage effect.

The value of asymmetric parameter for TGARCH $(1,1)$ process is negative, which means the volatility increases more with the bad news (negative shocks) than the good news (positive shocks) of the same magnitude for NSE index. This result is consistent with the finding of Wagala et al. [20], which used the ARCHtype process to model volatility of NSE weekly returns and provided with the evidence of volatility clustering and leverage effect. In our analysis, both GARCH $(1,1)$ and TGARCH $(1,1)$ models performed well to analyze the volatility clustering of stock returns, however, TGARCH $(1,1)$ outperformed GARCH $(1,1)$ model, mainly due to its ability to capture the asymmetry exhibited by the stock data.

The performance of these estimated models are determined on the basis of some accuracy measures. In our study, we compute the Akaike information criteria (AIC), Schwarz criteria (SC), and Root mean square error (RMSE). The results are displayed in Table 5. A look on the table reveals that there are not many differences seen among the values of accuracy measures obtained for all of five estimated models. Based on these measures, we may suggest that TGARCH $(1,1)$ is more suitable process to capture the main features of NSE return like the volatility and the leverage effect. We plot the observed and estimated NSE prices for the period from $19^{\text {th }}$ March 2013 to $18^{\text {th }}$ February 2016 in Figures 2(a)-(e). These graphs show a close match to the data exhibiting that these estimated 
econometric models provide a good fit to the observed NSE time series. However, a close look into these graphs would reveal that Figure 2(d) showed a better fit of TGARCH $(1,1)$ model to the observed NSE index because a smoother fitted curve can be seen.

Table 5. Some accuracy measures for different specifications of GARCH Models.

\begin{tabular}{cccc}
\hline GARCH models & AIC & SC & RMSE \\
\hline GARCH $(1,1)$ & -8.8247 & -8.7995 & 0.0032 \\
GARCH $=$ M $(1,1)$ & -8.8228 & -8.7913 & 0.0031 \\
EGARCH $(1,1)$ & -8.8173 & -8.7858 & 0.0032 \\
TGARCH $(1,1)$ & -8.8268 & -8.7953 & 0.0032 \\
PGARCH $(1,1)$ & -8.8318 & -8.7940 & 0.0032 \\
\hline
\end{tabular}

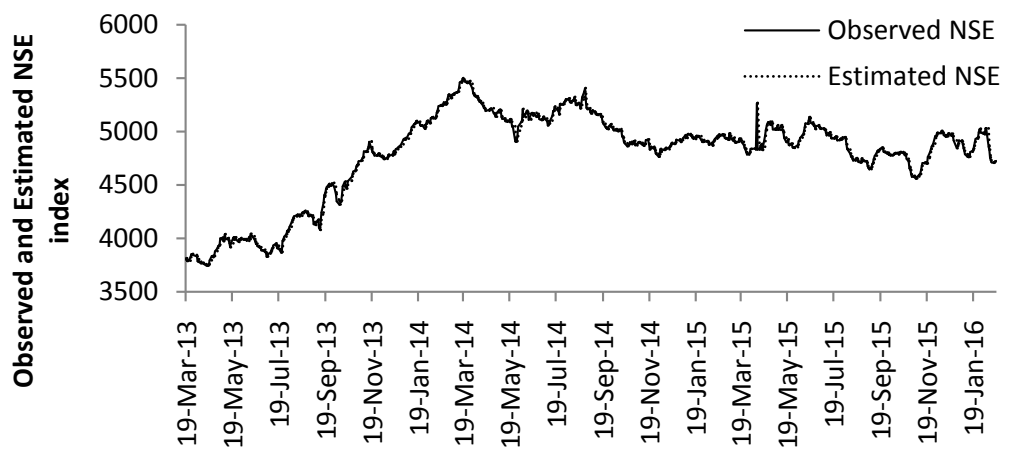

Time

(a)

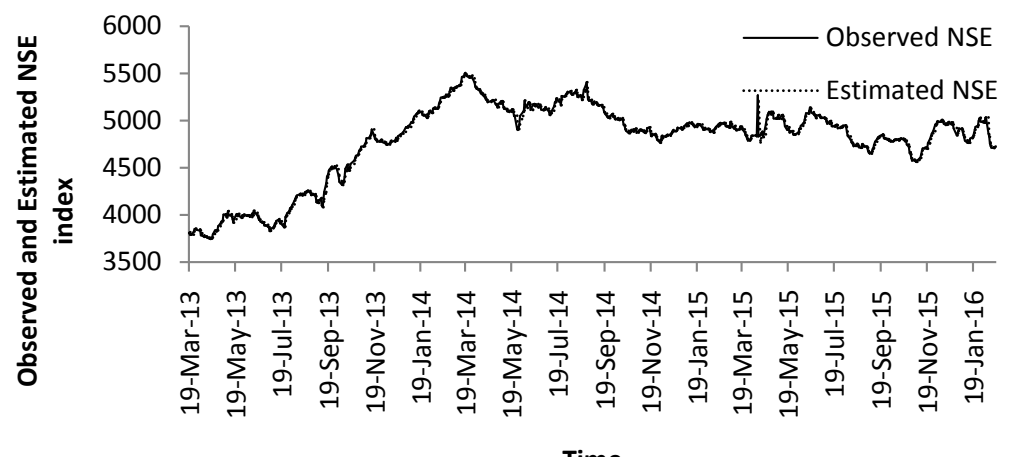

(b)

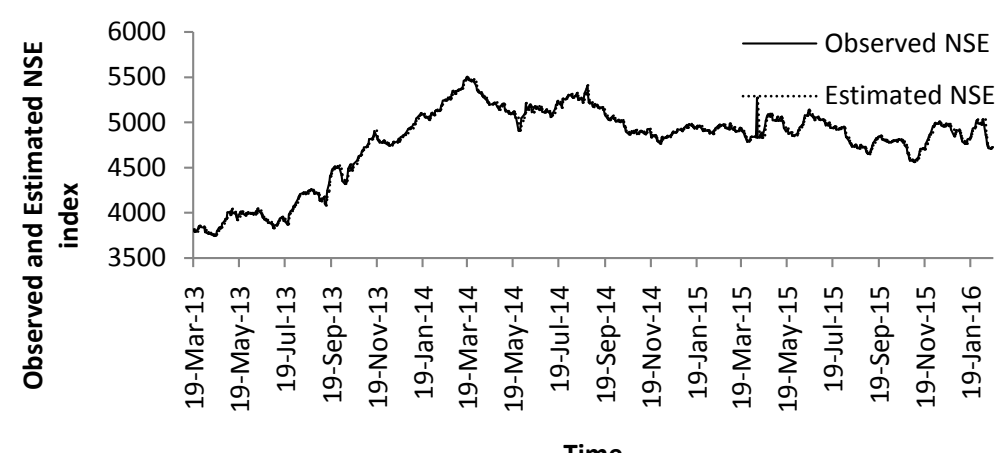

(c) 


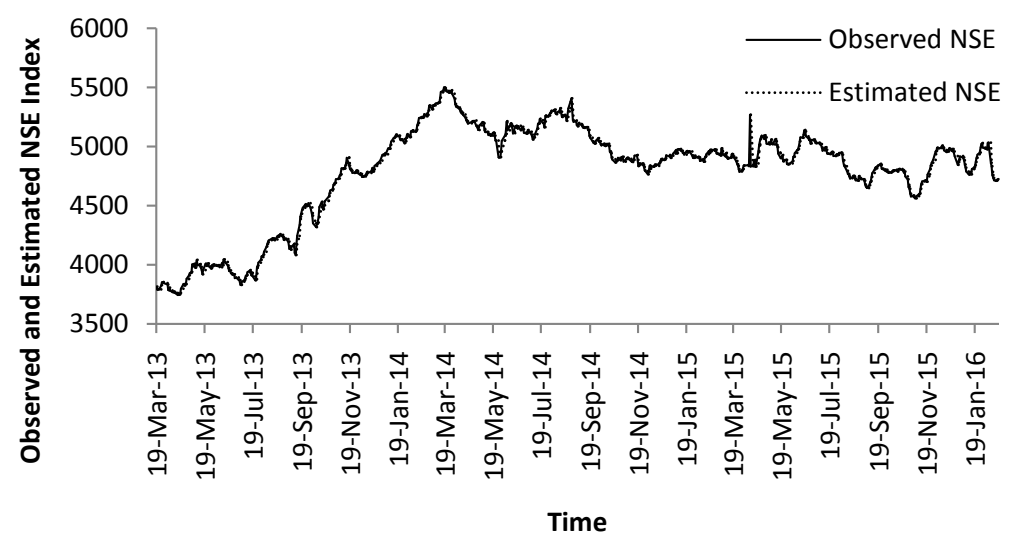

(d)

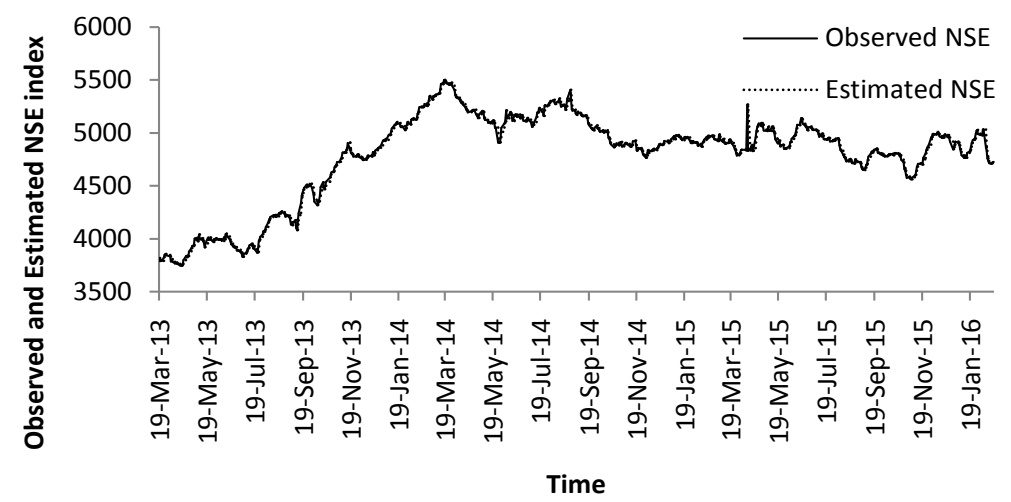

(e)

Figure 2. (a) Plot of observed and estimated NSE prices from GARCH $(1,1)$ Model. (b) Plot of observed and estimated NSE prices from GARCH-M $(1,1)$ Model. (c) Plot of observed and estimated NSE prices from EGARCH $(1,1)$ Model. (d) Plot of observed and estimated NSE prices from TGARCH $(1,1)$ Model. (e) Plot of observed and estimated NSE prices from PGARCH $(1,1)$ Model.

\section{Conclusion}

In this paper, we presented an empirical study to model the Nairobi securities exchange (NSE) using the family of GARCH models. Among many symmetric and asymmetric type heteroscedastic processes, we estimated GARCH $(1,1)$, GARCH-M (1,1), EGARCH $(1,1)$, TGRACH $(1,1)$, and PGARCH $(1,1)$ models. On one hand, the presence of volatility clustering is strongly confined from all these estimated models as we obtained the significant estimates corresponding to ARCH effect and GARCH effect parameters. The leverage effect in NSE return is also confirmed on the other hand. The asymmetric TGARCH $(1,1)$ model has the significant estimates of the leverage effect. By this analysis, we might say that the TGARCH $(1,1)$ model is more appropriate in term of capturing the volatility clustering and leverage effect of the NSE stock market.

\section{Acknowledgements}

The authors wish to thank the Department of Statistics, University of Karachi for providing the computing and research facilities. The authors thank to the ano- 
nymous referees of the journal "Open Journal of Statistics" for their helpful suggestions and comments.

\section{References}

[1] Engle, R. (1982) Autoregressive Conditional Heteroscedasticity with Estimates of the Variance of United Kingdom Inflation. Econometrica, 50, 987-1007. https://doi.org/10.2307/1912773

[2] Brooks, C. (2008) Introductory Econometrics for Finance. 2nd Edition, Cambridge University Press, Cambridge. https://doi.org/10.1017/CBO9780511841644

[3] Tsay, R.S. (2010) Analysis of Financial Time Series. 3rd Edition, John Wiley \& Sons, Inc., Hoboken. https://doi.org/10.1002/9780470644560

[4] Bollerslev, T. (1986) Generalized Autoregressive Conditional Heteroscedasticity. Journal of Econometrics, 31, 307-327. https://doi.org/10.1016/0304-4076(86)90063-1

[5] Posedel, P. (2005) Properties and Estimation of GARCH $(1,1)$ Model. Metodolskizvezki, 2, 243-257.

[6] Enders, W. (2004) Applied Econometric Time Series, 2nd Edition. In: Wiley Series in Probability and Statistics, John Wiley \& Sons, Inc., Hoboken.

[7] Patterson, K. (2000) An Introduction to Applied Econometrics: A Time Series Approach. Macmillan Press Ltd., London.

[8] Black, F. (1976) Studies of Stock Market Volatility Changes. Proceedings of the American Statistical Association, Business and Economic Statistics Section, 177181.

[9] Nelson, D. (1991) Conditional Heteroskedasticity in Asset Returns: A New Approach. Econometrica, 59, 347-370. https://doi.org/10.2307/2938260

[10] Glosten, L., Jagannathan, R. and Runkle, D. (1993) On the Relation between the Expected Value and the Volatility of the Nominal Excess Returns on Stocks. Journal of Finance, 48, 1779-1791. https://doi.org/10.1111/j.1540-6261.1993.tb05128.x

[11] Ding, Z., Engle, R. and Granger, C. (1993) Long Memory Properties of Stock Market Returns and a New Model. Journal of Empirical Finance, 1, 83-106. https://doi.org/10.1016/0927-5398(93)90006-D

[12] Bollerslev, T. (1987) A Conditionally Heteroscedastic Time Series Model for Speculative Prices and Rates of Return. The Review of Economics and Statistics, 69, 542 547. https://doi.org/10.2307/1925546

[13] Baillie, R. and Bollerslev, T. (1989) Common Stochastic Trends in a System of Exchange Rates. Journal of Monetary Economics, 44, 167-181.

[14] Liu, S. and Brorsen, B. (1995) Maximum Likelihood Estimation of a GARCH-Stable Model. Journal of Applied Econometrics, 10, 273-285. https://doi.org/10.1002/jae.3950100305

[15] Fernandez, C. and Steel, M. (1998) On Bayesian Modeling of Fat Tails and Skewness. Journal of the American Statistical Association, 93, 359-371. https://doi.org/10.1080/01621459.1998.10474117

[16] Ahmed, A.E.M. and Suliman, S.Z. (2011) Modeling Stock Market Volatility Using GARCH Models Evidence from Sudan. International Journal of Business and Social Science, 2, 114-130.

[17] Naimy, V.Y. (2013) Parameterization of GARCH (1,1) for Stock Market. American Journal of Mathematics and Statistics, 3, 357-361.

[18] Shamiri, A. and Isa, Z. (2009) Modeling and Forecasting Volatility of the Malaysian 
Stock Markets. Journal of Mathematics and Statistics, 5, 234-240.

[19] Kalu, O.E. (2010) Modeling Stock Returns Volatility in Nigeria Using GARCH Models. Munich Personal RePEc Archive, MPRA Paper No. 22723.

[20] Wagala, A., Nassiuma, D., Islam, A.S. and Mwangi, J.W. (2012) Volatility Modeling of the Nairobi Securities Exchange Weekly Returns Using the Arch-Type Models. International Journal of Applied Science and Technology, 2, 165-174.

[21] Sharma, P. and Vipul (2016) Forecasting Stock Market Volatility Using Realized GARCH Model: International Evidence. The Quarterly Review of Economics and Finance, 59, 222-230. https://doi.org/10.1016/j.qref.2015.07.005

[22] Engle, R., Lilien, D. and Robins, R. (1987) Estimating Time Varying Risk Premia in the Term Structure: The ARCH-M Model. Econometrica, 55, 391-407. https://doi.org/10.2307/1913242

[23] Engle, R. and Ng, V.K. (1993) Measuring and Testing the Impact of News on Volatility. The Journal of Finance, 48, 1749-1778. https://doi.org/10.1111/j.1540-6261.1993.tb05127.x

[24] Zakoian, J. (1994) Threshold Heteroscedastic Models. Journal of Economic Dynamics and Control, 18, 931-944. https://doi.org/10.1016/0165-1889(94)90039-6

\section{URL}

https://en.wikipedia.org/wiki/Nairobi_Securities_Exchange

https://www.nse.co.ke

http://www.investing.com/indices/kenya-nse-20-historical-data

Submit or recommend next manuscript to SCIRP and we will provide best service for you:

Accepting pre-submission inquiries through Email, Facebook, LinkedIn, Twitter, etc. A wide selection of journals (inclusive of 9 subjects, more than 200 journals)

Providing 24-hour high-quality service

User-friendly online submission system

Fair and swift peer-review system

Efficient typesetting and proofreading procedure

Display of the result of downloads and visits, as well as the number of cited articles

Maximum dissemination of your research work

Submit your manuscript at: http://papersubmission.scirp.org/

Or contact ojs@scirp.org 